\title{
Las facetas de España en el teatro de Manuel de Figueiredo: estudio preliminar*
}

\author{
Joana Castaño \\ Universidad de Oviedo/Universidade Nova de Lisboa (IELT) \\ castano.joana@gmail.com
}

Recibido: 18/11/2017

Aceptado: 30/07/2018

Nasci para cá dos Pyrineos.

(Figueiredo, 1805a, XI)

\section{RESUMEN:}

El diplomático y dramaturgo portugués Manuel de Figueiredo (1725-1801) es autor de una vasta obra dramática en la que a menudo ocurren referencias a España. El autor en uno de sus discursos se considera profundamente influenciado por la cultura y la lengua españolas. Así, en este trabajo nos planteamos discutir, aunque no sea de modo exhaustivo, los aspectos de la producción teatral de Figueiredo que remiten al universo español: (1) el idioma, (2) los tipos españoles, (3) la geografia y (4) la intertextualidad con originales españoles.

PALABRAS CLAVE: Teatro español, Teatro portugués, Siglo XVIII, Manuel de Figueiredo

* Una primera versión de este texto fue presentada en los II Seminarios Predoctorales en Investigaciones Humanísticas de la Universidad de Oviedo (2016). Este trabajo fue elaborado en el marco de una beca de doctorado de la Fundação para a Ciência e a Tecnologia (Portugal) (SFRH/BD/130926/2017). 
Spanish aspects in Manuel de Figueiredo's theatre.

\begin{abstract}
:
The Portuguese diplomat and playwright Manuel de Figueiredo (1725-1801) is the author of a vast work in which it is possible to find several references to Spain. He reveals in one of his speeches that he considers himself to be deeply influenced by the Spanish culture and language. Thus, in this work we set out to discuss, although not extensively, the aspects in Figueiredo's theatrical production that refer to the Spanish universe: (1) the language, (2) the Spanish types, (3) the geography and (4) the intertextuality with the Spanish originals.
\end{abstract}

KEYWORDS: Spanish theatre, Portuguese theatre, 18th Century, Manuel de Figueiredo

El diálogo entre Portugal y otras naciones ha sido una constante a lo largo de la historia de la Literatura Portuguesa ${ }^{1}$. Pese al intercambio cultural entre Portugal y España determinado por razones históricas y políticas, los contactos entre las dos naciones peninsulares no siempre han resultado positivos en el plano literario² $^{2}$ (Machado y Pageaux, 2001, 18).

1 El apartado «Diálogo entre o nacional e o estrangeiro» de Machado y Pageaux (2001, 16-21) ofrece una visión panorámica de estas influencias a lo largo de la historia de la Literatura Portuguesa. Sobre la presencia de Portugal y de temas portugueses en el teatro español, con especial enfoque en el siglo XIX, véase Peralta (2013).

2 Como señala Fernández García (1999), en el teatro portugués de los siglos XVI y XVII se verifica la presencia de estereotipos (nacionales y regionales) del castellano basados en diferentes estrategias dramáticas. En el caso de Gil Vicente y Francisco Sá de Miranda, la autora constata que el castellano se caracteriza por su «carácter fanfarrón» y por «la propensión a la expresión lirica», estereotipos que, en realidad, provienen ya del soldado fanfarrón de la tradición teatral grecolatina, y que Gil Vicente aproxima a la realidad portuguesa de principios del siglo XVI. La Aulegrafia (1619) de Ferreira de Vasconcelos introduce una imagen del castellano que se aleja de este modelo, en el sentido de que este personaje ocupa una posición central y demuestra una postura de superioridad frente a sus interlocutores lusos, y también porque la lengua es un aspecto fundamental en la construcción de la identidad del personaje. Por otro lado, este personaje le permite al autor «introducir sus opiniones sobre el bilingüismo literario y sobre las relaciones entre los dos pueblos» (Fernández García, 1999, 117-118, 125). 
En el siglo XVIII, época en la que Manuel de Figueiredo ${ }^{3}$ (1725-1801) desarrolló su proyecto dramático, la crítica señala que Portugal se alejó de la cultura española por cuestiones relacionadas con el prestigio nacional y se verificó una apertura hacia Francia e Italia (Picchio, 1969, 186-187). Aun así, el repertorio teatral español parece coexistir con la difusión del teatro francés e italiano y hay indicios ${ }^{4}$ que destacan la importancia que el teatro español seguía teniendo en la sociedad portuguesa ${ }^{5}$ (Bolaños Donoso y Reyes Peña, 1987, 1993; Bolaños y Peña, 1992; Barata, 2002; Gomes, 2012). Las ideas reformistas del teatro surgen como reacción a este contexto teatral, mientras que el primer intento de creación de una dramaturgia nacional ${ }^{6}$ aparece en 1756 con la Arcádia Lusitana, una academia literaria de Lisboa, de la que Figueiredo fue miembro con el pseudónimo de Lícidas Cíntio. En la biografía del árcade se constatan dos momentos clave en su relación con España: la participación en la Academia dos Ocultos ${ }^{7}$

3 Sobre la biografía de Manuel de Figueiredo véase Malato (1995), donde se ofrece una cronología detallada de la vida y la obra del autor.

4 Las informaciones que aportan los repertorios de las compañías tienden a concidir con lo que sucedía en Madrid, donde el teatro barroco se representaba cada vez menos (Andioc, 1987, 1-30).

5 Ha de referirse también que en la primera mitad del siglo XVIII se publican dos antologías de obras de teatro breve, en las que la mayoría de las piezas aparecen escritas en castellano: Musa jocosa (1709) y Flôr de entremezes, escolhidos dos mayores engenhos de Portugal e Castela (1717) (Barata, 1871, 83, 137). También las «mágicas» de autores españoles dieciochescos, como Salvo y Vela y José de Cañizares, o incluso del portugués António José da Silva (o Judeu), eran obras muy apreciadas por el público. Véase, por ejemplo, Os censores do teatro de Figueiredo, en la que se destacan los gustos del público (Figueiredo, 1804g).

6 Sobre el inicio del debate en torno al teatro nacional portugués, véase Marnoto $(2010,293-294)$

7 Esta academia «apresenta, no conjunto da sua produção, uma perspectiva similar da cultura dos escritores nacionais do final da época joanina. Se promove o conhecimento da literatura e das poéticas da Antiguidade, prefere ainda, e em geral, a grandiloquência castelhana à eloquência francesa. Cita-se Boileau, mas mais ainda 
(1745), muy arraigada aún a la tradición literaria española del Seiscientos, y su estancia en Madrid (1746-1753), durante la que Figueiredo desempeñaría funciones de secretario del embajador extraordinario de Portugal, D. Tomás da Silva Teles. En Madrid, el dramaturgo tuvo acceso privilegiado a la cultura española ${ }^{8}$, lo que podría justificar su pertenencia afectiva al espacio ibérico y la imagen ${ }^{9}$ positiva de España que se desprende del conjunto de su obra, ya lejos de la visión anti-castellana tan frecuente en la literatura portuguesa ${ }^{10}$. En efecto, en su producción dramática podemos comprobar varios aspectos pertenecientes al universo español que aportan nuevos datos para una mejor comprensión de las relaciones literarias entre Portugal y España en

a Luzán [...]. Privilegiando a expressão vernácula e latina, admite composições em língua castelhana, máxime nas formas e temas mais próximos da tradição barroca» (Malato, 1995, 97-98).

8 El catálogo de la biblioteca de Figueiredo incluye varias obras en castellano pertenecientes a diferentes estéticas literarias. Véase Catálogo.

9 Adoptamos la definición de Machado y Pageaux (2001, 51): «representação de uma realidade cultural estrangeira através da qual o indivíduo ou o grupo que a elaboram (ou que a partilham ou que a propagam) revelam e traduzem o espaço ideológico no qual se situam».

10 En el discurso de $A$ mulher que o não parece (1774), el autor subraya su relación personal de afecto con los españoles mediante el uso del posesivo «meus»: «Cheguei a casa, abro Aristophanes, pégo nos Latinos, vejo os Italianos, dous Inglezes, que por acaso allí tinha, os meus amigos Castelhanos, huma, e outra Poética (das que tratão disto) [número de personajes] e principiei a rir-me da triste figura, que tinha feito» (Figueiredo, 1804e, [X]). Por otra parte, también se valoran positivamente las «semcerimonias» en las formas de tratamiento en España, esto es, el aprecio de los españoles por el trato llano y sencillo, un tema presente a lo largo de la obra de Figueiredo: «E nós [espanhóis e portugueses], por mais/Raianos que sejamos, que nenhumas/Outras duas Nações: nossos costumes,/E nossas paixões, mesmo, sobre pouco/Mais, ou menos desdizem; entendemo-nos/Fallando cada huma a sua lingoa;/Mas encanta-me aquelle trato llano,/Essas semcerimonias, de que a nossa/ Conserva tantos restos, que a sua já/Bannio, e condemnou» (Figueiredo, 1806, 113). Véase también la nota 2. 
el siglo XVIII ${ }^{11}$. Para ello, en este trabajo consideraremos algunos ejemplos extraídos de la obra del dramaturgo que permiten documentar la presencia de España y analizaremos (1) el uso de lengua española, (2) la presencia de personajes españoles, (3) los espacios geográficos circunscritos al territorio español y (4) la intertextualidad ${ }^{12}$ con originales castellanos. Sin embargo, debido a la amplia obra de Figueiredo y a su compleja estructuración dramática, no cabe en este trabajo un análisis exhaustivo de cada una de las categorías consideradas. Se trata de un trabajo preliminar y nos proponemos en el futuro desarrollar estos aspectos de forma más pormenorizada. En este momento asumimos como principio metodológico el consejo: «Quem muito abrange, pouco aperta» (Figueiredo, 1804d, 57).

\section{La lengua}

A lo largo de la obra de Figueiredo comprobamos, de manera general, la utilización del portugués como lengua de redacción y la defensa de su empleo como lengua dramática, como ya habían hecho autores del Renacimiento portugués como Sá de Miranda y António Ferreira. Por otro lado, el autor critica en la dedicatoria a su Teatro la calidad de las traducciones portuguesas -«vemos a frase Portugueza mais adulterada nos escritos dos Comicos, que na boca dos Estrangeiros, de poucos mezes chegados a Lisboa»

11 Como sugieren Machado y Pageaux (2001, 19), «uma justa revalorização do papel de desempenhado por certos homens, por vezes «menores» em literatura, como criadores propriamente ditos, mas cuja importância no diálogo das culturas é considerável, só pode ser útil para uma melhor compreensão das relações literárias entre nações». Sin embargo, no creemos que la importancia de la obra de Figueiredo se circunscriba apenas a su biografía, sino que su dramaturgia se reviste de gran interés bajo varios puntos de vista.

12 Adoptamos las definiciones de «intertextualidad» e «intertexto» propuestas por Aguiar e Silva $(2000,625)$, basadas en los estudios de Julia Kristeva: «intertextualidade como a interacção semiótica de um texto com outro(s) texto(s) e intertexto como o texto ou o corpus de textos com os quais um determinado texto mantém aquele tipo de interacção». 
(Figueiredo, 1804b, [7])- y observa cómo algunos castellanos cuestionaban la utilización del idioma español por parte de los autores lusitanos ${ }^{13}$, en detrimento del portugués, lengua a la que reconocían «a gravidade, a energia e a suavidade» (Figueiredo, 1810, XIV).

Por otra parte, Figueiredo considera que su estancia en Madrid influyó en su dominio de la lengua materna y se reconoce castellanizado: «vivi sete anos entre castelhanos, cuja semelhança de idioma não só me fez perder a acção da minha lingoa; porém mil vezes me faz entrar na dúvida de serem, ou não Portuguezes os termos» (Figueiredo, 1810a, XIX). También José Xavier de Valadares e Sousa, censor del Édipo de Sófocles presentado por Figueiredo a la Arcádia Lusitana (1757), señaló esta interferencia del castellano en la redacción de la versión portuguesa de la tragedia griega: «na primeira Scena do 3..$^{\circ}$ Acto, na Antistrophe do Acto 4. , verso 205, 214, e 227 se acha monstruo, que he dicção Castelhana» (Figueiredo, 1810a: 93). Si el dramaturgo se disculpa con la «precipitação, com que se copiou a Tragedia», en este caso particular confirma que el término es «certamente Castelhanada» y ofrece una explicación de lingüística contrastiva: «nem todas as dicções acabadas em anos no plural Castelhano fazem no Portuguez em anos, ou em ãos. Os Castelhanos Escrivanos, e Enanos, e nós não dizemos Escrivãos, e Anãos» (Figueiredo, 1810ạ, 124).

Aunque se verifique el interés de Figueiredo por la revitalización del portugués como lengua literaria, en la producción dramática del autor constan dos obras escritas en castellano. La primera, El engaño escarmentado en los castigos del zelo, inaugura su obra dramática y fue escrita en Madrid en 1748 y corregida ya en Lisboa en 1757. Su estructura externa sigue la división en jornadas del teatro español del Siglo de Oro, manteniendo el soliloquio, un aspecto que será criticado por el árcade en sus discursos. Sin embargo, Malato $(1995,107)$ señala ya en esta primera obra ciertas contradicciones estéticas, una vez que la praxis 
incluye tanto normas barrocas como la adopción de estrategias de ruptura que aparecen en obras más tardías. La otra obra en castellano, Los amantes sin ochavo (s/d), es un «sainete de música» que incluye acotaciones en portugués. Resulta curioso que no tengamos noticia del término en cuanto tipología teatral hasta el siglo XX, por lo que podemos apuntar que, en este caso, Figueiredo parece ser el único autor que adapta un género breve muy popular en España en la segunda mitad del siglo XVIII ${ }^{14}$. En este caso, apuntamos que la tipología elegida estaría notoriamente asociada a España y determinaría de alguna manera el idioma adoptado.

Por otro lado, también en varias de las obras escritas en portugués como, por ejemplo, en Mapa da Serra Morena (1774) y O fatuinho (1773), se verifica el recurso a refranes o expresiones idiomáticas españolas por personajes portugueses, un rasgo que ya está presente en la obra de autores anteriores:

\section{Probo.}

Sim, ficando Cada loco...

\section{Solis.}

He verdade, con su têma.

(Figueiredo, 1804d, 300)

\section{Eugenio.}

Sim, bem sei

Vamos ao outro

Rosmunda.

O outro, como dizem os Castelhanos.

Le dieron calabazas.

(Figueiredo, 1804d, 486) 
En ciertas ocasiones, tanto los personajes españoles como los portugueses hablan en portugués, como ocurre en el Avaro dissipador (s/d), en Mapa da Serra Morena, en Apologia das damas (1773) o en Lúcia ou A espanhola (s/d), supuestas traducciones de originales españoles, como tendremos oportunidad de ver a continuación; en otros casos, los personajes portugueses y españoles hablan idiomas distintos, según su nacionalidad, y hay comprensión mutua, pero se verifica el intento de reproducir la forma de hablar de un tipo regional, el gallego o el andaluz, como en Poeta em anos de prosa (1773) y en $O$ fatuinho. Una vez que este tópico está estrechamente relacionado con el apartado siguiente, volveremos a ello a continuación.

\section{Los personajes españoles}

En cuanto a los personajes españoles en la obra de Figueiredo, podemos mencionar tipos regionales, como el andaluz y el gallego, y varios personajes castellanos. En este apartado consideraremos las damas, los aristócratas, los cómicos y algunos personajes populares.

En la obra $O$ fatuinho (cuya acción tiene lugar en Idanha-aVelha, cerca de la frontera con España) aparece un personaje andaluz, y Figueiredo se sirve de su variedad lingüística con fines cómicos. La siguiente acotación introduce la caracterización física del personaje y lo singular de su manera de hablar:

Perico com chapéo branco desabado, calções de anta, largos no joelho, Arrieiro Andaluz, \&c. cachimbando, e fallando sem S, mui chibante, como elles são: e cicioso afectadissimo.

(Figueiredo, 1804d, 386)

Resulta también curioso que Palatino, un hidalgo de origen portugués, comente la forma de hablar del andaluz Perico, un arriero de pocas «zalamarias», con lo que el autor demuestra un buen conocimiento de las particularidades lingüísticas de esta región española: 


\section{Perico.}

Utè sabe de Almagro?

Palatino.

Me escalavras, Perico, co'esse Usted.

Perico.

Mire Dom Palatino; en mi lugá

Ai quatro Cavalleros Hijos d'algo,

Titulos de Castilla; y mire utè:

Desde Circuncision a Navidá

$\mathrm{Ni}$ una vez si quiera ze zantiguan

Con tal Señoria; y oiga utè:

Sabe por lo que riñen, por el Tu.

(Figueiredo, 1804d, 388)

También se hacen patentes en la misma obra los desvíos lingüísticos del portugués cuando se esfuerza en hablar castellano y se destaca el tuteo español, tan poco habitual entre portugueses:

\section{Palatino.}

Tu dizes cuesas...

\section{Perico.}

Digo cosas!.. Por l'alma de mi abuela,

Por este puñadito, si, de cruces

Yo se lo juro a utè; que entre los grandes

Ha habido mil camorras: Que camorras!

Pero por ninérias! Por la usia?

Que l'e visto en Italia, y por acá...

$[\ldots]$

\section{Palatino.}

El Tu, es una cosa

Tan rara, tan notable, que en ninguna Otra parte del Mundo, que en España

La conocen, Amigo; pues reñir... 
Como contrabandista por la usia,

Que utè saca por alto: es ser petate!

(Figueiredo, 1804d: 388-389, el destacado es nuestro)

Para Camões (2007a, 12), el efecto cómico producido por personajes portugueses que intentan hablar un idioma extranjero ya es frecuente en el teatro del siglo XVI ${ }^{15}$. En el siglo XVII, también la Carta de Guia de Casados (1651) de Francisco Manuel de Melo señala el «tu» como forma de tratamiento característica del castellano y la preferencia del portugués por la tercera persona:

$\mathrm{O} \mathrm{Tu}$ he Castelhano e por mais que elles o achem carinhoso, como lá dizem, é palavra muito de praça e que ao mais não deve de quebrar a menagem da câmara para fóra. [...] O Ele e Ela, um Ouve Senhor, Que diz Senhora, é termo bem português, assaz honesto e bem soante.

(Melo, 1996, 177)

Así, Figueiredo, pone en evidencia el gusto de los portugueses por las cortesías y las ceremonias y, en una acotación, manifiesta la importancia de la forma de tratamiento en la propia representación ${ }^{16}$ : «Sorrindo-se de ver arripiar Palatino a ouvir o usted, que diz mais alto» (Figueiredo, 1804d, 388).

Otro tipo muy habitual de la obra de Figueiredo es el gallego. De acuerdo con González Lopo (apud Pazos Justo, 2011, 41), desde el siglo XVIII hasta mediados del XX Lisboa fue uno de los principales destinos de emigrantes gallegos, que se encarga-

15 El Auto de Florisbel supone un ejemplo de la dificultad de comunicación entre personajes que hablan lenguas diferentes (Camões, 2007a, 12). También el Auto dos sátiros, el Auto dos enanos, el Auto de Dom Luís e dos turcos y la Comédia da pastora Alfea, los dos primeros de autor desconocido y el último de Simão Machado, incluyen ejemplos del empleo de la lengua española (Camões, 2007b, 2007c; Camões, Rodríguez, y Reis, 2009). En particular, sobre el uso del castellano en la obra de Simão Machado, véase Camões, Rodríguez y Reis (2009, 45-50).

16 Véase el fragmento de la página 15. 
ban de realizar trabajos no cualificados, lo que será determinante para la creación de una imagen negativa de este grupo social (Pazos Justo, 2011, 39-42). La imagen del gallego que presenta el teatro de Figueiredo corrobora las afirmaciones de Pazos Justo (2011), ya que este siempre aparece como trabajador de clase social baja («gallego de esquina», «mariola» o criado doméstico), que se encarga de trabajos pesados, poco educado y cuyo principal objetivo es ganar dinero, como resulta patente en la comedia A mulher que o não parece:

hum Gallego de esquina com huma cama atada em huma esteira, que larga na casa, e sahe.

(Figueiredo, 1804e, 57)

Jovial.

O mariola

Lhes diria que estava na Cadeia,

E julgarão-me prezo: coitaditas.

O que terão chorado! Fortes brutos!

$[\ldots]$

Para ajuntar dinheiro únicamente

Tem arte estes Gallegos: são uns brutos.

Não prestão para nada mais.

(Figueiredo, 1804e, 58, el destacado es nuestro)

En un pasaje de Poeta em anos de prosa, se refleja la forma de hablar portugués del gallego, dando cuenta en la ortografía de la sustitución sistemática de la consonante labiodental fricativa $<\mathrm{v}\rangle$ por la oclusiva $<\mathrm{b}>^{17}$ :

\section{Raymundo.}

Logo á primeira

Conheceo a doença o bom do Medico:

17 En un texto coetáneo, Assembleia ou a Partida (1770) de Correia Garção, este rasgo no se verifica. 
Tem o demo no corpo estes Doutores;

Estrangeiros parece que adebinhan.

(Figueiredo, 1804b, 178, el destacado es nuestro)

Sin embargo, en el caso del criado doméstico detectamos un retrato más amable del gallego, tal vez fundamentado en la relación de complicidad entre señor y criado. Por otra parte, el término «gallego» se utiliza incluso en sentido genérico para designar una persona que quiere ganar dinero ávidamente, como se desprende de este fragmento de Fastos de amor e amizade (s/d):

\section{Marcella.}

Dá-me tanta raiva,

Não perder os costumes de villã.

Dinheiro! Que dinheiro! Algum Gallego

He que busca dinheiro.

(Figueiredo, 1804d, 28)

En O dramático afinado (1773), en una escena en la que describe el gusto del público por el teatro de magia, el gallego es comparado a otras figuras que son despreciadas por su baja cultura:

\section{Poeta.}

Tire lá isso.

Vão enganar crianças e gallegos, algum preto buçal de Cabo Verde:

já lá vai esse tempo, meus amigos.

(Figueiredo, 1804c, 53-54)

Por su parte, en Mapa da Serra Morena, las damas españolas son caracterizadas por su gran atractivo, con «vestidos justos a Hespanhola» (Figueiredo, 1804d, 249). En Apologia das damas, aparecerá una «meretriz», Lycori, con trajes escotados que provocan comentarios como: 
Luiz.

Tape-se lá, Senhora, que eu também

Caio nas tentações.

(Figueiredo, 1804c, 276)

Genaro.

Pelo trage

Parece del Barquillo.

(Figueiredo, 1804c, 292)

Como señala Martín Gaite $(1972,31)$, en España a partir del siglo XVIII se produce un cambio en la moda y comienzan a ser subvertidos algunos de los criterios de la centuria anterior. Así, la forma de vestir que distinguía a cortesanas de damas (en relación, por ejemplo, al escote del jubón) había ido evolucionando y el lujo había dejado de ser considerado inmoral. Por último, cabe puntualizar que en más de una ocasión los personajes femeninos madrileños (la criada Brígida o las damas Dorinda y Carina) se caracterizan por su astucia:

Luiz.

He muito esperta.

Brigida.

Sou Madrilenha, e basta.

(Figueiredo, 1804c, 334)

D. Probo.

Mas temo que se ajuntem [Dorinda y Carina], e mo esganem:]

Hão de vir a fazello, conhecendo-o.

Tu o verás! São raio as Madrilenhas.

(Figueiredo, 1804d, 279)

En $O$ avaro dissipador, la aristocracia española aparece como gran aficionada al teatro y a los ricos manjares. Hay situaciones 
en que es evidente en los personajes portugueses un cierto temor a hacer el ridículo delante de los castellanos, supuestamente más refinados:

\section{Cozinheiro.}

Não senhora: faltavão peças fortes.

Mas cá o seu Vigario nos mandou

Huma boa vitella, que nos deixa

Sem mais que desejar: eu estimei-o;

Porque esses Castelhanos não tivessem

Que dizer do banquete, que elles tratão-se.

(Figueiredo, 1806, 81)

Queda también claro de esta comparación entre ambas naciones que Portugal es «hum Paiz sem Theatro» (Figueiredo, $1806,114)$ y con un cierto retraso cultural en relación a lo que ocurre en España. A pesar del esfuerzo de la Corona en presentar «tudo o que ha de mais notavel [...] no cómico, bufão, heroico, e trágico", el pueblo sigue prefiriendo comedias de magia, como por ejemplo Don Juan de Espina (1713) de José de Cañizares o El mágico de Salerno (1715) de Juan Salvo y Vela, de las cuales «já nem fumos há» en los teatros españoles (Figueiredo, 1806: 115). $\mathrm{Al}$ gusto por el teatro se añade el aprecio por las actrices por parte de los nobles españoles ${ }^{18}$, como lo demuestra la intervención del marqués de $O$ avaro dissipador $(\mathrm{s} / \mathrm{d})$, una pieza que describe la llegada de una compañía de la legua a Portugal, camino de Lisboa:

\section{Marquez.}

Porém eu nem sou Santo, nem Filosofo

18 Según Martín Gaite (1972, 103), «las actrices en la segunda mitad del XVIII, no se consideraban seres vulgares [...]. Y su trato y compañía no sólo no desdoraban, sino que prestigiaban». En el contexto portugués, Braga $(1871,9)$ relata un episodio galante protagonizado en Lisboa por una actriz española, Zabel Gamarra, que «deu egualmente volta á dignidade da fidalguia de Lisboa». 
Eu o Primeiro sou do meu lugar.

Entrar no vestuario toda a sorte

De galopim, de traste; e condemnar-me

A porta o Empresario, he desaforo,

Que não hei de sofrer, e se hei de ir lá

Para obrar, ou fazer qualquer acção

Menos digna de mim, mais desgraçada,

Melhor he que não volte.

(Figueiredo, 1806, 160)

En $O$ avaro dissipador figuran también cómicos de una compañía de la legua, que, en complicidad de un marqués español y un barón portugués, intentarán engañar a la mujer del barón, haciéndose pasar por aristócratas. Al llegar a casa de los barones, en Portugal, los cómicos españoles son presentados por el criado Jerónimo como familiarizados con la lengua portuguesa, lo que reflejaría la presencia habitual de las compañías de la legua en Portugal ${ }^{19}$ :

\section{Jeronymo.}

Fallão o Portuguez

Como nós; porque allí póde dizer-se,

Pelo comercio que ha, e pelo tráfico

Entre as duas Nações, que mais se falla

Portuguez, que Hespanhol; ainda a Marqueza

Falla muito mais claro que o marido,

E nunca poz os pés em Portugal;

Quanto mais estas Comicas, que já

$\mathrm{O}$ tem corrido quasi.

(Figueiredo, 1806, 66)

19 En el discurso que precede esta obra, Figueiredo se refiere a la afición que existía en Portugal por la música y el teatro en lengua castellana: «o sabor, que o primeiro leite nos faz achar nas composições naquella lingua» (Figueiredo, 1806, XI). En la pieza es manifiesta la presencia de este tipo de compañías por todo el país: «Estiverão nas Caldas, em Setuval,/ Por todo o Ribátejo; e ultimamente/ Tres annos haverá, lá no Theatro/ De Belém» (Figueiredo, 1806, 66). 
Cuando la primera cómica se hace pasar por la marquesa de Carina y le pide a otra actriz que no hable (temiendo que esta no resulte lo suficientemente convincente para engañar a la baronesa), surgen interesantes consideraciones sobre una lengua hablada en el norte de España, seguramente el euskera:

\section{Dama.}

Chegou-nos hontem

De Bilbáo; e desculpe-a, que não sabe

Fallar mais do que a lingoa Celtiberia,

Ou ribadávia: lingoa, que o diabo,

Inda dando-se perros, nunca póde

Entender, ou ouvir: desafinada,

E tão algaravia he a maldita.

(Figueiredo, 1806, 124)

Asimismo, en el sainete Los amantes sin ochavo también constan personajes populares, vendedoras de limas y barquillos, estudiantes de Salamanca y un alguacil, una serie de tipos que, en cierta medida, nos remiten al universo del teatro breve de Ramón de la Cruz. En el fragmento que presentamos a continuación, dos vendedoras madrileñas, provenientes de barrios populares, replican a dos estudiantes (amantes suyos, que manifiestan no tener dinero para sustentarlas y que les ofrecen, a cambio, su corazón y su sangre):

\section{Paquita.}

Diganlo alas madamas, alas usias,

Que essas son las que gastan Salamerias.

\section{Pepita.}

No corre entre nós otras esse estribillo; Essa es de Lavapies, yo del Barquillo.

(Figueiredo, 1806, 175) 


\section{La geografía}

Son sin duda la ciudad de Madrid y sus cercanías los territorios españoles que aparecen con mayor frecuencia en la obra de Figueiredo. Así, hay obras cuya acción tiene lugar en Madrid (como Apologia das damas ${ }^{20}$ ) o en Aranjuez (como Mapa da Serra $\left.M o r e n a^{21}\right)$, y en las que se hace alusión a locales de la élite madrileña como la Fontana de Oro (Mapa da Serra Morena ${ }^{22}$ ) y a barrios populares de la capital española (Apologia das damas y Los amantes $\sin$ ochavo $^{23}$ ).

En otras ocasiones, la toponimia no se limita simplemente a localizar espacialmente la acción, posibilitan el elogio de la capital española, la comparación entre el ambiente lisboeta y madrileño e introducen una diferente percepción de la realidad por parte de portugueses y españoles:

\section{Leonor.}

Todo o Mundo he Paiz.

Lycori.

Mas sempre ouvi, que nelle não havia outra Madrid.

(Figueiredo, 1804c, 197)

20 Por ejemplo, Leganés, Alcalá, Leganitos, Vistillas o el Prado (Figueiredo, $1804 \mathrm{c}, 182,190,218,228,230,244,249,298)$.

21 Por ejemplo, Calle de la Reina, Jardín de los Negros, Getafe, Chamberí, Fontana de Oro, Calle de las Carretas o el Buen Retiro (Figueiredo, 1804d, 198, 201, 215, $219,226,227,237,280,299,335,338$ ).

22 Por ejemplo, dice el personaje Estriga: «Boa dúvida./ Deixei os meus baús na Fonte de ouro: O Mercador, coitado, accommodou-se,/ Porque se me prendesse, nem ouvíra/ Esta doce palavra, hei de pagar-lhe,/ Se Deos me der fortuna (Figueiredo, $1804 d, 215-16)$.

23 Véase el fragmento de Los amantes sin ochavo presentado en el apartado anterior. 


\section{Rodrigo.}

Se os ares de Madrid lhe são fataes, poderá ser, Senhor, que os de Lisboa lhe sejão favoraveis, e acabemos.

\section{Diogo.}

Isso são muchachadas, D. Rodrigo, tão honrado tem sido o Portuguez, que desde que sonhou que o assombrava, pé me não poz em casa, e já me dizem que se anda despedindo o Embaixador.

(Figueiredo, 1804c, 219)

\section{Vasco.}

Vem, ou vai-se della?

Lycori.

Vamo-nos.

Vasco.

Para longe?

Lycori.

E muito longe.

\section{Vasco.}

Os longes de Madrid, são como os pertos de Lisboa.

(Figueiredo, 1804c, 224)

Otra localización habitual es la raia luso-española, que permite trazar un hábil contraste entre Portugal y España, en particular en $O$ avaro disipador. Esta comedia, al situar la acción en una región de la raia, señala una frontera geográfica que le sirve de excusa a Figueiredo para contraponer el carácter nacional de ambos países ${ }^{24}$. Además, es esa frontera la que permite deshacer el oxímoron propuesto en el título de la pieza, puesto que el noble portugués se comporta como tacaño en Portugal y como 
despilfarrador en España: «Passo-me allí á Raia, e nas caçadas,/ Com Comicos, Siganas, e Novillos/Lhe dou fogo [ao dinheiro]» (Figueiredo, 1806, 35). En O fatuinho el personaje andaluz Perico, al que ya nos hemos referido, permite al autor (mediante el contraste de la utilización de las formas de tratamiento en España y Portugal) introducir una crítica al gusto lusitano por las cortesías y las pretensiones hidalgas. En el fragmento siguiente, el arriero Perico ridiculiza el portugués Palatino, una vez que desprecia su gusto por las apariencias y lo apareja como si fuera un animal de carga. Así, también aquí el discurso mímico y verbal aparecen asociados:

\section{Palatino.}

Las armas y la Usia son el ámago

De la Nobleza. En mi...

\section{Perico.}

Es encertada

En el arbol de Quina. De estimable

No tiene que la cáscara.

\section{Palatino.}

Nada mas,

Que albardar un burrico.

\section{Perico.}

Yo no puedo.

\section{Perico.}

Apoiar-se un poquito en las rodillas, Para capacitar este muchacho;

Mira de aqui, de alli, de acá, de allá.

(Figueiredo, 1804d, 394)

Por otro lado, como indica su título, en la comedia Mapa da Serra Morena aparecen referencias a Andalucía ${ }^{25}$. Sin embargo, en esta obra las referencias más significativas son a la ciudad de

25 «E por lá [Lisboa] não haver navio prompto,/ Vem embarcar a Cadis» (Figueiredo, 1804d, 263). 
Madrid o a Aranjuez. A nuestro entender, la referencia a Sierra Morena se debe a la trama de la obra, en la que suceden una serie de robos y fugas que permiten introducir una comparación con este territorio español "poco apacible e incomodo» (García-Romeral Pérez, 2000, 12) y que se caracterizaba por la presencia de bandoleros ${ }^{26}$ (Ruano, 1761, 305).

En un fragmento de esta misma obra, un personaje español, el jugador Estriga, pretende irse a Lisboa para hacer fortuna y el paje Pepe lo desengaña con una descripción de lo que encontrará allí y una apología de la permanencia en España, en «qualquer Provincia deste Reino»:

\section{Pepe.}

Mas tu julgas, Estriga, Portugal

Paiz de Manicocos? Ou presumes,

Que as ruas de Lisboa são calçadas

De fina pedraria, ou muros, casas,

Ser todas de calháos de ouro maciço?

Não são tal, eu já as vi: e sempre ouvi,

Fallando do Brazil, e do Perú,

Que quem não leva India, não traz India:

Ha de lembrar-te a Patria. Ou vás fazer-te

Toureiro, Volatim, Comediante,

Que he só no que por lá se exercitava

Todo aquelle infeliz, que daqui sahe com esse teu destino, essa equipagem?].

(Figueiredo, 1804d, 216)

26 Sin embargo, se constata a lo largo de la obra la presencia de léxico como «contrabandos», «piratas», «ladrões», «ladrãozinho», corsário» (Figueiredo, 1804d, $237,264,345,346,347)$ 
A semejanza de algunas tragedias españolas neoclásicas ${ }^{27}, \mathrm{Lu}$ cia ou a espanhola nos remite a territorios americanos que pertenecían al Imperio español y no se inspira en la historiografía nacional como Viriato (1757), Ósmia (1773), Inês (1774) o As irmãs (1775). Aunque Figueiredo reconozca la falta de historias adecuadas a la tragedia (Figueiredo, 1810a: XVI), resulta curioso que el autor alegue traducir un original español que tiene como tema la conquista de América y que no se moleste en identificar inequívocamente a su autor, como hace para el Édipo (1757) de Sófocles o el Artaxerxes (1757) de Eurípides, como discutiremos en el punto siguiente.

\section{Intertextualidad con originales castellanos}

Por último, nos referiremos a la intertextualidad con referencia a obras literarias españolas, analizando de qué modo el intertexto ${ }^{28}$ se manifiesta en la obra de Figueiredo. En este sentido, discutiremos las relaciones dialogales que se establecen con originales castellanos, sean explícitas o no, y las funciones que desempeñan en el sistema semiótico literario. Como señala Aguiar y Silva, «a metalinguagem do neoclassicismo justifica e impõe a função corroboradora» e, en general, «semântica e pragmaticamente [...] toda a intertextualidade [...] nunca é ideologicamente inocente ou asséptica, reenviando sempre [...] a uma cosmovisão, a um universo simbólico em que se acredita ou que se denega» (Aguiar e Silva, 2000, 632-33).

Figueiredo afirma en los discursos que preceden a Lucia ou a espanhola y a Apologia das damas que se trata de obras traducidas

27 «Aparecen a partir de 1776, y son, junto con Doña María Pacheco (1788), de Ignacio García Malo, las obras que escenifican los hechos de la historia española menos alejados en el tiempo: Hernán Cortés (1776), de Alexis Piron, traducida por Alonso Pérez de Guzmán, duque de Medina Sidonia; Moctezuma (1784), de Bernardo María de Calzada; Atahualpa (1784), de Cristóbal María Cortés, que ha merecido una edición moderna; y El triunfo de la moral christiana, o los americanos, título que recibe en la traducción del citado Bernardo María de Calzada Alzire (1736), de Voltaire, tragedia por otra parte que tuvo más versiones en español» (Sala Valldaura, 2005, 389).

28 Véase la nota 12. 
de originales en lengua castellana. Sin embargo, en el caso de la primera pieza, hemos constatado que en la portada del manuscrito del tomo XI de la Biblioteca Nacional de Portugal (ms. COD. 4484), la tragedia aparece atribuida a un tal D. Gabriel Triaquero (Figueiredo, [70]). El supuesto dramaturgo se corresponde con un autor ficticio que aparece en la Histoire de Gil Blas de Santillane de Lesage (1715-1735) ${ }^{29}$. En la novela de Lesage, Gil Blas asiste en Valencia a una tragedia del supuesto Gabriel Triaquero, ante cuya popularidad un caballero madrileño lamentará las críticas al modelo tradicional de Lope y Calderón. Así, Triaquero (el presunto autor de Lucia ou a espanhola, obra «traduzida fielmente do castelhano ${ }^{30}$ ) propondría una ruptura con la tradición teatral del Siglo de Oro y abogaría por los principios de la Ilustración. Sin embargo, hasta el momento no ha resultado posible identificar las supuestas fuentes españolas de estas piezas (si es que no se trata de una estrategia de Figueiredo para esconder su propia autoría). En todas las otras traducciones, en su mayoría de obras francesas, el autor original está debidamente identificado (Figueiredo, 1810a, [501-504]).

La comedia $O$ fatuinho, a semejanza de lo que suele pasar con las obras trágicas, también aparece acompañada de un «Argumento Histórico» en castellano, extraído del Catálogo real genealógico de España: ascendencias y descendencias de nuestros Catolicos Principes y Monarcas Supremos ${ }^{31}$ de Rodrigo Mendes da Silva, de la Historia general de España ${ }^{32}$ de Juan de Mariana y de Política moral e civil: aula da nobreza Lusitana ${ }^{33}$ de Damião Faria e Castro, sobre el

29 Según una edición portuguesa contemporánea, el término «triaquero» significa «charlatán» $\mathrm{y}$ «dissimula um ataque contra Voltaire» (Lesage, 1977, 192).

30 De acuerdo con el manuscrito de la Biblioteca Nacional de Portugal (ms. COD. 12995), la tragedia Lucia ou a espanhola sería la traducción de una comedia famosa redactada en castellano, Lucia no Paraguay.

31 Silva $(1656,24-25)$.

32 Mariana $(1855,179)$.

33 Castro (1754, 142). 
rey Wamba, «un caballero principal de la Real sangre Gotica, natural de la Ciudad de Idaña» (Figueiredo, 1804d, [356-357]). Así, en nuestro entender, al apoyarse en estos textos pertenecientes a la historiografía peninsular sobre la ascendencia y fortuna del rey Wamba - que «traxo por armas una vacia, como suelo de confitero, y en ella dôs Caracoles, significando la renunciacion que de su voluntad hizo del Reyno; quedando sin pompa, magestad, ni riquezas...» (Figueiredo, 1804d, [1])-, Figueiredo sustenta sus criticas a las pretensiones nobiliarias de la naciente burguesía ${ }^{34}$. El recurso al historicismo, aunque las fuentes manifiesten su naturaleza legendaria, permiten al autor presentar el rey godo como ejemplo de modestia y, en una de las versiones, descendiente «de hum pobre lavrador, que nos campos da Idanha em Lusitania alimentava a vida com o suor do rosto» (Figueiredo, 1804d, [2]).

Así, esta obra corrobora la observación de Peralta a propósito del teatro portugués de la segunda mitad del siglo XVIII: «el decaimiento de los modelos italianos imperantes -incluido el ámbito musical - pero también de la comedia española, favorecerá una paulatina mirada hacia temas locales ante la creciente presión del historicismo» (Peralta, 2013, 47). Por otra parte, Augustín de Montiano y Luyando ${ }^{35}$ en una de las primeras tragedias neoclásicas españolas, Ataúlfo (1753), recurre también a un tema histórico peninsular, tomado de la Crónica General y «tampoco la política merece especial atención, perdida entre los problemas de los celos del primer rey godo y la traición de Sigerico, Vernulfo y Rosmun-

34 Rebello aproxima O fatuinho e João Fernandes feito homem (1756) a la Assembleia ou a Partida (1770) de Correia Garção y al O falso heroísmo (1775) de Cruz e Silva, en el que se estigmatiza «falsa ideia da nobreza bebida desde o berço» (Rebello, 1989, 80-81).

35 A finales de 1752, período en el que Figueiredo estaría todavía en Madrid, Montiano y Luyando era miembro del «Consejo de su Majestad, su Secretario de la Cámara de Gracia, y Justicia, y Estado de Castilla, Director perpetuo por S. M. de la Real Academia de la Historia y Académico de la Real Academia Española» (apud Berbel Rodríguez, 2001, 122). 
$\mathrm{da}^{36}{ }_{\gg}$ (Sala-Valldaura, 2005, 203). De esta forma, tanto la obra de Figueiredo como la de Montiano y Luyando recurren en su argumento a un tema común de la historia de Portugal y España ${ }^{37}$.

Por otra parte, también desde el prólogo de su Theatro (publicado por primera vez en 1775, y que incluye obras de 1773 y 1774), el Quijote es presentado como un referente fundamental de Figueiredo. El autor compara la recepción negativa de su obra por cierta parte de la crítica (que no ha sido capaz de comprenderla) con lo que le ocurrió en su momento a Cervantes. Además de las referencias al Quijote y a otros personajes cervantinos, el uso del término «quixotadas» es muy frecuente:

\section{Vasco.}

Sempre he douda!

Você será parenta daquela Ama

de D. Quixote?

(Figueiredo, 1804b: 221)

\section{Vernulfo.}

Ora minha Fidalga, demos fim

A tanta quixotada, que estas Fabulas

Não são obra, mulher, de Dom Eugenio,

Ou imaginação de algum Poeta.

(Figueiredo, 1804d:541)

Referencias a teóricos españoles están también presentes en los discursos, epígrafes y en las propias obras dramáticas de Figueiredo. Por ejemplo, en el discurso de Alberto Virola (s/d), Figueiredo se sirve de las afirmaciones de Luzán en «De los defectos más comunes de nuestras comedias» (1737), relativas a la falta de calidad de las comedias españolas, para argumentar la

36 Vernulfo y Rosmunda, un matrimonio de labradores ricos que habita la finca del rey Wamba, aparecen como personajes en la comedia de Figueiredo.

37 En la Comedia Auleografia (Vasconcelos, 1619, 151) también la hidalguía aparece asociada al origen godo: «Fidalgo mais que os Godos». 
imposibilidad de crear obras dramáticas a partir de obras españolas:

O famoso Luzan ornato do Parnaso Hespanhol, que criticando a sua Nação, ou os Poetas della, provou mais de patriota que ainda de Filosofo; joeirando todo o seu Theatro, só quinze lhe não cahirão do crivo [...]; ficando o Theatro, que todos os mais procurárão imitar, o Hespanhol digo, sem hum modelo digno para os nossos dias.

(Figueiredo, 1804f, [IV-V])

También el epígrafe de Poeta em anos de prosa consiste en un fragmento de un poema de Tomás de Iriarte publicado con su traducción de la Epístola a los Pisones (1777), en el que se reconoce la importancia de Horacio a la hora de distinguir una obra dramática de calidad (Figueiredo, 1804e, 160). Por último, la marquesa española de $O$ avaro dissipador comenta las complejas relaciones entre Portugal y España, aludiendo a un discurso del padre Feijoo en su Teatro Crítico Universal (1779 [1728]):

\section{Marqueza.}

Somos raianos,

E Feijó prova bem, que dahi vinha

Toda a animosidade conhecida

Entre Turcos, e Persas: nós também

Não lhes devemos nada.

(Figueiredo, 1806, 112)

También encontramos referencias de Figueiredo a obras dramáticas españolas, tanto en los textos de carácter teórico como en las propias obras. En este primer ejemplo, tomado del discurso de Ensaio cómico (1774), se menciona la obra Reinar después de morir (1652?) de Vélez de Guevara (uno de los hipotextos de la Ignez de Figueiredo) a cuya representación el autor habría asistido en su tierna infancia y también en edad adulta, originando las dos situaciones impresiones muy diferentes: 
Suspirando eu quatorze, ou quinze annos por tornar a ver aquella Comedia, e tendo espias nos Theatros de Madrid, onde não perdi nenhuma nos primeiros seis mezes, tendo tarde libre: Reinar despues de morir, foi a primeira, que não pude supportar nem até o meio; sahi, e como corrido, e envergonhado de haver-me agradado ainda na idade de seis ou sete annos.

(Figueiredo, 1804g, [II])

También en la comedia Apologia das damas se hace referencia a La venganza venturosa (1618) de Lope de Vega. En este caso, se cita una intervención de Celio, personaje de esta comedia de Lope, que recibe una carta de su novia portuguesa y elogia el idioma portugués:

\section{Genaro.}

Mas aquelles ares

De Portugal, Senhor, não sei que tem

Mais a favor do sexo, que os demais

Da Europa. Diz Lope (quando nada)

Asta la lengua parece, que es también enamorada.

(Figueiredo, 1804c, 287)

En otro caso, el libro El Diablo Cojuelo (1641) aparece en escena como atrezzo, como muestran las acotaciones: «Busca o livro no chão, e levanta-o»; «Mostra-lhe a estampa do livro» (Figueiredo, 1804c: 287, 288). El criado Genaro imagina un viaje de su amo portugués, Vasco, en compañía del diablo, semejante al emprendido por el protagonista de la novela de Vélez de Guevara. El francés Luís, no obstante, parece despreciar el libro elegido por Genaro:

\section{Genaro.}

Quem he?

Luiz.

Sou eu. 


\section{Genaro.}

Perdoe, que estava lendo El Diablo Coxuelo.

Luiz.

Boa especie!

Genaro.

Queria refrescar-lhe na pintura

Da guardilha do Magico.

Luiz.

E porque?

\section{Genaro.}

Porque foi entregar aquella carta,

Que meu amo me deo no Galetás,

Agua furtada, ou seja mesanino

Do tal licenciado; e já sonhei

Cousas extravagantes, e a proposito.

Luiz.

Raro humor, que sonhaste?

\section{Genaro.}

Que o Diabo

Partira com meu amo pelos ares,

E lá desde a Giralda de Sevilha,

Destelhadas as casas de seu Pai,

Lhe mostrava Isabel, que em soliloquio

Bocados de ouro diz, chorando a môco

Môco tendido, sobre o seu retrato.

(Figueiredo, 1804c, 287-288)

Y cabe mencionar también la comparación de un personaje de Apologia das Damas con la Celestina, protagonista de la obra de Fernando de Rojas. La expresión utilizada parece haber sufrido un proceso de popularización, en el sentido en que se aleja de su fuente literaria ${ }^{38}$ :

38 Aún en la misma obra, hay un pasaje en la que se constata la presencia de una expresión popular que da nombre a la comedia de Lope de Vega, El perro del 


\section{Diogo.}

Embora! Não permita que esta Madre

Celestina se escape, toda a trama

Foi urdida por ella: ella a perdeo.

(Figueiredo, 1804c, 328)

\section{Conclusiones}

En este punto, nos parece indudable que España tiene una presencia significativa a lo largo de la obra de Manuel de Figueiredo (tanto en sus discursos como en sus piezas teatrales), que se hace patente a través de diferentes ejes o facetas. Con respecto al uso del castellano como lengua dramática, comprobamos cómo Figueiredo conoce las diferentes variedades lingüísticas del español y de otras lenguas peninsulares. No obstante, a pesar de que haya una notoria preferencia por el portugués como lengua dramática, el autor también recurre a menudo a expresiones castellanas y, por consiguiente, sería oportuno revisar la dramaturgia portuguesa del siglo XVIII para analizar el empleo del castellano por los escritores coetáneos. Por otra parte, la aparición de personajes de origen español no siempre determina el uso del castellano y la lengua no suele funcionar como un aspecto fundamental en la construcción de la identidad del personaje, con excepción del retrato de tipos regionales (el gallego y el andaluz). Cabe destacar, también, la intención manifiesta de reproducir el discurso oral.

La caracterización de los tipos españoles considerados en este trabajo requiere un análisis más profundo; sin embargo, atendiendo a los ejemplos presentados: el gallego se ocupa de tareas desprestigiadas en la sociedad portuguesa del siglo XVIII y anhela enriquecerse; la mujer española (sea dama o cortesana) resulta muy atractiva a los ojos de los portugueses, y la madrileña es presentada como un personaje astuto; los nobles aprecian el teatro y la compañía de las actrices; $y$, finalmente, las majas y

hortelano (1618): «Porém ella que fez? Sempre clamei,/Que este Jacob, mulher, e esse casquilho/Havião ser o perro do hortelão. Dizia mal?» (Figueiredo, 1804d, 169). 
otros personajes procedentes de los barrios populares madrileños nos remiten a ejemplos del teatro breve español. En cuanto a la ambientación geográfica, Madrid y sus cercanías son los lugares mencionados con mayor frecuencia, lo que en cierta medida no resulta extraño debido a la estancia de Figueiredo durante aproximadamente siete años en la capital española. Sin embargo, aunque los referentes espaciales se destinen a localizar la acción, suelen aparecer asociados a valoraciones sobre el territorio español o introducen la exposición de diferencias entre Portugal y España. También sorprende que una de las tragedias de Figueiredo-original o no- se aparte de temas nacionales portugueses y adapte una historia sobre la conquista española de América. En cuanto a las relaciones intertextuales con textos de la literatura española, se reconoce una posición poco favorable de Figueiredo en relación al teatro español del Siglo de Oro y una convergencia con las ideas neoclásicas de autores como Feijoo, Luzán, Montiano y Luyando e Iriarte. Sin embargo, las referencias no siempre manifiestan la corroboración o la negación de un modelo teatral español, sino también la utilización de expresiones consagradas por la literatura española de forma autónoma. Así, Figueiredo consideraría que el público lector/espectador portugués sería capaz de comprender la carga semántica de estas expresiones.

Por todo lo expuesto en este análisis preliminar, a pesar de la constatación de la frontera que separa ambas naciones, consideramos que la obra de Figueiredo contribuye a redefinir la relación entre las dos naciones ibéricas y manifiesta la notable proximidad a España y a los españoles.

\section{Referencias bibliográficas}

Aguiar e Silva, V. M. (2000) Teoria da Literatura, Coimbra, Almedina.

Andioc, R. (1987) Teatro y sociedad en el Madrid del siglo XVIII, Madrid, Fundación Juan March y Editorial Castalia.

Araújo, T. (2007) «A dramaturgia de autores portugueses em língua espanhola (Séculos XVI-XVIII)», Revista à Beira, 157-76. 
Barata, J. O. (1991) História do teatro português, Lisboa, Universidade Aberta.

(2002) «A dramaturgia portuguesa seiscentista e oitocentista», en AA. VV., História da literatura portuguesa: da época barroca ao pré-romantismo, Vol. 3, Lisboa, Alfa, 223-261.

Berbel Rodríguez, J.J. (2001) «La tragedia Ataúlfo de Montiano y el concordato de 1753», RLit, 125, 115-128.

Bolaños Donoso, P. y M. de los Reyes Peña (1987) «Tomás Pinto Brandão: la comedia de comedias. Introducción, edición y notas», Criticón, 40, 81-159.

(1993) «Presencia de comediantes españoles en el Patio de las Arcas de Lisboa (1700-1750)», en El escritor y la escena, Ciudad Juárez, Universidad Autónoma de Ciudad Juárez, 229273.

(1992) «El teatro español en Portugal (1580-1755) estado de la cuestión», en Dramaturgia e espetáculo, $1 .^{\circ}$ congresso lusoespanhol de teatro, Coimbra, Livraria Minerva, 61-81.

Braga, T. (1871) História do theatro portuguez. A baixa comédia e a ópera (século XVIII), Porto, Imprensa Portuguesa.

(2005), História da literatura portuguesa: recapitulação, Os árcades, Lisboa, INCM.

Câmara, M. A. y V. Anastácio (2005) O teatro em Lisboa no tempo do Marquês de Pombal, Lisboa, Museu Nacional do Teatro.

Camões, J. (2007a) Teatro português do século XVI (I), Vol. I, Lisboa, INCM. boa, INCM.

(2007b) Teatro português do século XVI (I), Vol. II, Lisboa, INCM.

(2007c) Teatro português do século XVI (I), Vol. III, Lis-

Camões, J., J. J. Rodríguez, y H. Reis (2009) Comédias de Simão Machado, Lisboa, INCM.

Camlong, C. (1993) «La poétique de Manuel de Figueiredo», Arquivos do Centro Cultural Português, 32, 127-177.

Castro, D. A. L. F. (1754) Politica moral e civil: aula da nobreza Lusitana, Vol. VI, Lisboa, Officina de Francisco Luiz Ameno. 
Castaño, J. (2017) «Los amantes sin ochavo: ¿el primer sainete portugués?», Anagnórisis. Revista de investigación teatral, 15, 412-442.

Catálogo dos livros impressos e mss. que doou à R. Bibliotheca Publica da Corte o Ill. mo Snr Tenente Coronel Francisco Coelho de Figueiredo, Biblioteca Nacional de Portugal (ms. COD. 4476).

Cortesão, J. (1984) Alexandre de Gusmão e o Tratado de Madrid, Vol. I-III, Lisboa, Livros Horizonte.

Cruz, R. de la (1990) Sainetes, Francisco Lafarga (ed.), Madrid, Cátedra.

Feijoo, B. J. (1779 [1728]) «Antipatía de franceses y españoles», en Teatro crítico universal, Vol. II, Madrid, Joaquín Ibarra, 223-229.

Fernández de Moratín, L. (2000) La comedia nueva o El café, Joaquín Álvarez-Barrientos (ed.), Madrid, Biblioteca Nueva.

Fernández García, M. J. (1999) «Personajes castellanos en el teatro portugués del siglo XVI», Anuario de estudios filológicos, XXII, 113-29.

Figueiredo, M. (1804a) Obras posthumas, Vol. I, Lisboa, Imprensão Régia.

(1804b) Theatro de Manoel de Figueiredo, Vol. I, Lisboa, Imprensão Régia.

Imprensão Régia.

(1804c) Theatro de Manoel de Figueiredo, Vol. II, Lisboa, Imprensão Régia.

(1804d) Theatro de Manoel de Figueiredo, Vol. III, Lisboa, Imprensão Régia.

(1804e) Theatro de Manoel de Figueiredo, Vol. IV, Lisboa, (1804f) Theatro de Manoel de Figueiredo, Vol. V, Lisboa, Imprensão Régia. Imprensão Régia.

(1804g) Theatro de Manoel de Figueiredo, Vol. VI, Lisboa, (1805a) Theatro de Manoel de Figueiredo, Vol. VII, Lisboa, Imprensão Régia. 
(1805b) Theatro de Manoel de Figueiredo, Vol. XI, Lisboa, Imprensão Régia.

(1806) Theatro de Manoel de Figueiredo, Vol. XII, Lisboa, Imprensão Régia.

(1810a) Theatro de Manoel de Figueiredo, Vol. XIII, Lisboa, Imprensão Régia.

Régia.

(1810b) Obras posthumas, Vol. II, Lisboa, Imprensão

Theatro de Figueiredo, Vol. XI, Lisboa, Biblioteca Nacional de Portugal (ms. COD. 4484).

Lucia no Paraguay: comedia famoza traduzida fielmente da lingua castelhana, Lisboa, Biblioteca Nacional de Portugal (ms. COD. 12995).

García-Romeral Pérez, C. (2000) Bio-bibliografía de viajeros por España y Portugal: Siglo XVIII, Madrid, Ollero \& Ramos.

Gomes, Francisco L. R. F. (2012) O Teatro da Graça na segunda metade do século XVIII. Tese de Mestrado, Faculdade de Letras da Universidade de Lisboa.

IRIARTE, T. de (1777) «Discurso preliminar», en El arte poético de Horacio o Epistola a los Pisones, Madrid, Imprenta Real de la Gazeta, III-LIII.

Lesage, A. R. (1977) Gil Blas de Santillane, M. Correia (trad.), Lisboa, Amigos do Livro.

Machado, Á.M. y D.H. Pageaux (2001) Da Literatura Comparada à Teoria da Literatura, Lisboa, Editorial Presença.

Malato, M. L. (1995) Manuel de Figueiredo: uma perspectiva do neoclassicismo português (1745-1777), Lisboa, INCM.

(2002) «A utopia neoclássica: História do movimento arcádico», en AA.VV., História da literatura portuguesa: da época barroca ao pré-romantismo, Vol. 3, Lisboa, Alfa, 263-317.

Mariana, J. (1855) Historia general de España, Madrid, Imprenta y Librería Gaspar y Roig.

Marnoto, R. (2010) História crítica da literatura portuguesa: do Neoclassicismo ao Pré-Romantismo, Vol. IV, Lisboa, Verbo. 
Martín Gaite, C. (1972) Usos amorosos del dieciocho en España, Barcelona, Anagrama.

Melo, F.M. (1996) Carta de guia de casados. Pedro Serra (ed.), Braga, Angelus Novus.

Pazos Justo, C. (2011) «A imagem da Galiza e dos galegos em Portugal entre fins do século XIX e primeiras décadas do XX: do imagotipo negativo ao imagotipo de afinidade», Veredas, 16, 39-70.

Peralta, B. (2013) «Portugal en el teatro político e histórico español del siglo XIX», Historia y Política, 29, 45-73.

Picchio, L. S. (1969) História do teatro português, Lisboa, Portugália.

Rebello, L. F. (1989) História do Teatro Português, Lisboa, Europa-América.

Ruano, F. (1761) Historia general de Córdoba, Córdoba, Francisco Villalón.

Sala-Valldaura, J. M. (1995) «La conquista de América en la tragedia neoclásica española». En Actas del XXIX Congreso del Instituto Internacional de Literatura Iberoamericana, Tomo II, I, Barcelona, P.P.U, 85-103.

(2005) De amor y política: la tragedia neoclásica española, Madrid, Editorial CSIC.

Silva, R. M. (1656) Catálogo real genealógico de España: ascendencias y descendencias de nuestros Catolicos Principes y Monarcas Supremos, Madrid, Imprenta de Doña Mariana del Valle.

Vasconcelos, J. F. (1619) Comedia Aulegrafia, Lisboa, Craesbeeck.(Figueiredo, 1804c, 287-288) 
